\title{
ランチョンセミナーI
}

\section{Turapy - Transurethral Ablation Prostatectomy by High Temperature Radiofrequency-Preliminary Results of A Multicenter Study.}

\author{
(University Clinic of Brussels, Erasme Hospital)
}

\section{C.C. SCHULMAN*}

\section{Abstract}

Thermal treatment of BPH has been introduced several years ago as an alternative treatment modality for patients suffering from symptomatic $\mathrm{BPH}$. The initial temperatures ranged from 44.5 to $48^{\circ} \mathrm{C}$. With these temperatures, about $60 \sim 70 \%$ of the patients showed significant improvement of their subjective, mainly irritative symptoms with only mild changes in their obstructive parameters. In order to improve the therapeutic effects, increase in energy delivered allowing higher temperatures in the order to $70 \sim 100^{\circ} \mathrm{C}$ was investigated regarding the feasibility, tolerance, pathological lesions and clinical effectiveness. A new radiofrequency technique, TURAPY - TransURethral Albation Prostatectomy, an outpatient ablative BPH treatment has been introduced recently. The treatment is applied transurethrally with a helicoidal antenna without any cooling system. Temperature delivery in the order of medium $75^{\circ} \mathrm{C}$ was applied during a

* Multicenter Study ;

1. Prof. C. Schulman, Dr. L. Hourriez, Erasme Hospital, University Clinic of Brussels.

2. Prof. S. Arap, Dr. P. Goes, Hospital das Clinicas, Universidad de Sao Paulo, Brazil.

3. Mr. Shiv Bhanot, M.D., K.M. Grigor, T.B. Hargreave, G.D. Chisholm, University Dept. of Surgery \& Urol., Western General Hospital, Edin. burgh, Scotland.

4. Prof. I. Nissenkorn, Dr. D. Simon, Meir General Hospital, Tel-Aviv University, Israel.

5. Prof. A. Corica, A. Marianetti, R. Anchelerguez, J. Prats, M. Consoli, Dept. of Urol., University of Cuyo-Mendoza, Argentina. medium time of 45 minutes.

An ongoing multicenter study* included 38 patients. 15 patients were operated by retropubic prostatectomy after $6 \sim 30$ days, for a histopathology study and 23 eligible patients were entered in a clinical study and analyzed to determine the efficacy of the TURAPY treatment.

The tolerance was excellent and although patients experienced initial heating sensation at the onset of treatment, as the temperature rose to 40 $\sim 50^{\circ} \mathrm{C}$ (as with previous modalities of thermotherapy), they did not experience further pain and the procedure was never stopped.

Urinary retention was observed in about $80 \%$ of the patients, due to the extensive tissular destruction. These patients had suprapubic catheter inserted one day to a maximum of one week (medium 3 days). Pathological findings of the operated specimens showed extensive coagulative necrosis of all tissular components of the prostatic tissue (glandular elements, fibromuscular stroma), extending up to $40 \mathrm{~mm}$ from the urethra.

Magnetic resonance imaging (MRI) was performed before and after TURAPY. Absence of captation of Gadolinium in $\mathrm{T} 2$ sequences was seen in areas of the prostate corresponding to the necrosis seen in the pathological specimens.

Cystourethroscopy showed the prostatic urethra filled with necrotic tissue, with constant sluffing of the dead tissue and cavity formation at 8 weeks.

The symptom score improved from 22 to 7 (mean values) at the 3 month follow up. Peak flow rate increased on average from $5.3 \mathrm{ml} / \mathrm{sec}$ to $9.7 \mathrm{ml} / \mathrm{sec}$ 
at 1 month and to $13.3 \mathrm{ml} / \mathrm{sec}$ at 3 months. Postvoiding residual volume decreased from a mean value of $181 \mathrm{ml}$, with 3 patients in retention to $78 \mathrm{ml}$ (1 month) and improved further to $52 \mathrm{ml}$, with 1 patient in retention (3 months).

The peak flow rate significantly improved (defined as a change of $50 \%$ or more) in $82 \%$ of the patients at the 1 month follow up. The histopathology and clinical results establish Turapy as a safe and effective treatment of $\mathrm{BPH}$, in relieving patients of irritative symptoms as well as obstructive symptoms, in a single, anesthesia free, 1 hour outpatient session.

Introduction

Conventional treatment for BPH in recent decades has been transurethral resection of the prostate (TURP) or open prostatectomy, depending on adenoma volume. Although TURP is widely perceived by urologists as successful in the long term in $80 \%$ of patients, there is some morbidity and certain failure rate ${ }^{1) 2}$. Urologists have been searching for an effective but safer treatment ${ }^{3)}$. Alternative treatments include pharmacology treatment ${ }^{4) 5}$, ballon dilation ${ }^{6)-8)}$, urethral stents $^{9}$, and hyperthermiathermotherapy ${ }^{10)-14}$.

The WHO committee on benign prostatic hyperplasia has defined the various heat treatment technologies for $\mathrm{BPH}^{15}$.

Hyperthermia and thermotherapy is defined as heat treatment at a temperature range of $42 \sim 60^{\circ} \mathrm{C}$. Heat treatment in this range relieves irritative symptoms in about $60 \sim 70 \%$ of the patients, with only mild changes in obstructive parameters ${ }^{10)-14)}$.

Thermal treatment in excess of $70^{\circ} \mathrm{C}$ reliably destroys all human living tissues and is termed as thermal tissue ablation ${ }^{16)}$. At these temperatures extensive coagulative necrosis occurrs. Thermal tissue ablation of BPH can be produced with Lasers, High Intensity Focussed Ultrasound and Shock Waves $^{17) \sim 19)}$.

A new radiofrequency technique, TURAPY - TranUrethral Ablation Prostatectomy, an outpatient ablative BPH treatment has been introduced recently. TURAPY causes extensive ablation of tissue around the prostatic urethra, similar to the laser. This paper presents the feasibility, tolerance, pathological lesions and clinical effectiveness of TURAPY--TransURethral Ablation Prostatectomy.

Patients and Methods

Patients were selected fulfilling the following inclusion and exclusion criteria ;

Inclusion criteria ;

1. Symptomatic BPH

2. Peak flow rate $<10 \mathrm{ml} / \mathrm{sec}$.

3. Prostatic volume $<80 \mathrm{gm}$ and $>25 \mathrm{gm}$.

4. Distance from prostatic urethra-rectal wall $>$ $1.5 \mathrm{~cm}$.

5. Distance from bladder neck to vermontanum $>3.5 \mathrm{~cm}$.

Exclusion criteria :

1. Cardiac pacemaker

2. Metallic prosthesis in the hip or knee joint.

3. Suspicion of neurological bladder dysfunction.

4. Presence of bladder neoplasm/calculus/diverticulum.

5. Bleeding diathesis.

6. Impaired mental state.

Histopathology study

15 patients were operated by retropubic prostatectomy following Turapy treatment. Macrospecimens of the operated prostate were examined and histology microspecimens were taken.

Magnetic Resonance Imaging (MRI) was performed before and after Turapy. Patient evaluation included transrectal ultrasound and cystourethroscopy performed before and after treatment.

Interstitial thermal mapping was performed measuring temperatures at different locations of a cross section of the prostate.

Clinical study

23 patients meeting the inclusion criteria underwent a complete physical examination including; blood analysis, uroflowmetry, determinations of postmicturation volume by bladder ultrasound, measurement of the prostatic volume by transrectal ultrasound and prostate specific antigen (PSA) level. 
The patient's irritative symptoms were monitored by the Madsen symptom score ${ }^{20)}$.

The treatment was administered on an outpatient basis, in a one hour session with temperatures of 70 $\sim 80^{\circ} \mathrm{C}$ using the Turapy device (Direx Medical Systems Ltd.). A 16 French catheter equipped with a heating antenna and two thermosensors for temperature monitoring is inserted into the prostatic urethra. Temperature is monitored in three locations for safety ; in the prostatic urethra, at the external sphincter and in the rectum.

Patients were catheterized by suprapubic catheter following treatment for a period of 3 days to a maximum of 1 week.

Irritative and objective parameters were assessed before treatment and at one and three months follow up.

\section{Results}

Patient tolerance and complications:

The patient tolerance was excellant and all patients completed the one hour session of treat. ment. Several patients experienced initial spasm and heating sensation at the onset of treatment, as the temperature rose to $40 \sim 50^{\circ} \mathrm{C}$, as with the previous modalities of thermotherapy. Following this very transient sensation, the patients did not experience further pain.

Immediatly following Turapy treatment urinary retention was observed in approximately $80 \%$ of the patients. These patients had a suprapubic catheter inserted one day to a maximum of 1 week (medium of 3 days) and thereafter voided satisfactorily. In 4 patients symptoms of urinary retention persisted for more than 2 months. 2 of these 4 patients had a growth of coliforms on urine culture which required antibiotic treatment for 2 weeks.

Histopathology :

Macrospecimens of the operated prostate showed extensive lesions in the entire prostate. Histological microspecimens showed completely destroyed phantomatic prostate glands (Case Study 2). Coagulative necrosis and vascular infarct was seen in most of the tissue. The necrotic lesions extended up to $40 \mathrm{~mm}$ (mean $32 \mathrm{~mm}$ ) deep around the urethra, with no preservation of stromal or glandular tissue. In several patients, with prostatic glands not exceeding $30 \mathrm{cc}$, the coagulative necrosis extended to more than half of the prostate surface (Fig. 1).

Magnetic Resonance Imaging (MRI) showed absence of captation of Gadolinium in T2 sequences in areas of the prostate corresponding to the ne-

Fig. 1 Macroscopic view of a prostate specimen removed by open surgery after TURAPY showing extensive coagulative necrosis extending $4 \mathrm{~cm}$ around the urethra.

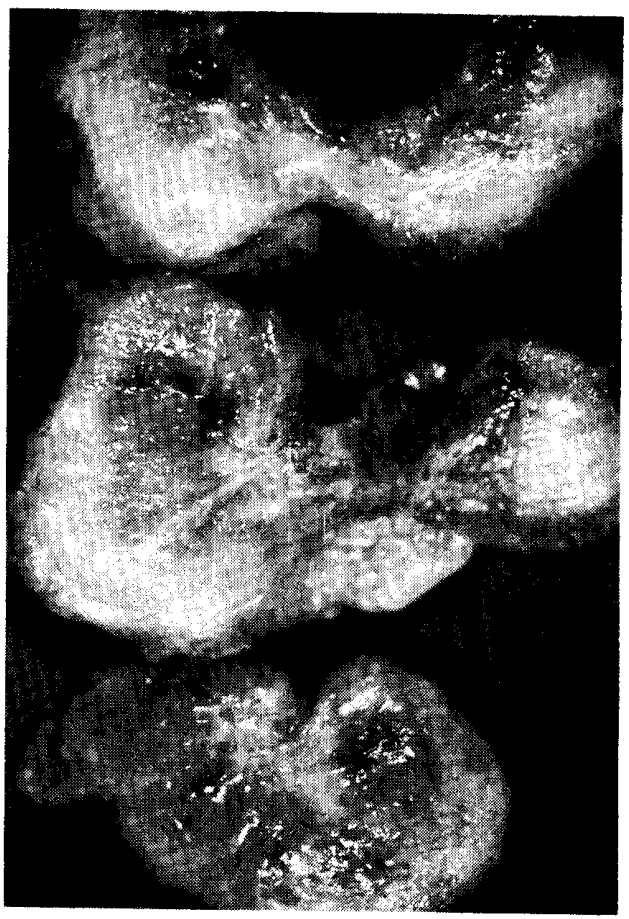

Fig. 2 MRI after TURAPY showing a large central cavity in the prostate compared to a TURP cavity (arrow).

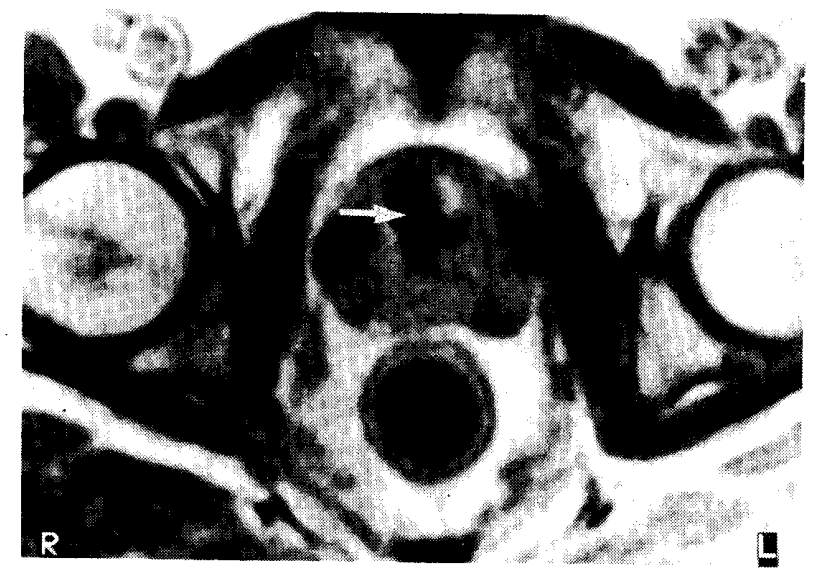


crosis seen on the pathological specimens (Fig. 2).

On transrectal ultrasound opening of the prostatic urethra with shrinkage of the preiurethral zone was demonstrated. The cavity formation was observed at twelve weeks. Prostatic volume measured in 12 patients, showed a mean reduction from $53.2 \mathrm{ml}$ to $37.4 \mathrm{ml}$, three months after Turapy.

Interstitial thermal mapping in patients during treatment measured a mean temperature of $77^{\circ} \mathrm{C}$ in the prostatic urethra and a mean temperature of $40^{\circ} \mathrm{C}$ in the area near the rectum. At a cross section of the prostate, temperatures reached $79^{\circ} \mathrm{C}$ at $0.5 \mathrm{~cm}$ from the urethra and $75^{\circ} \mathrm{C}$ at $0.6 \mathrm{~cm}$ from the urethra and dropped to $50^{\circ} \mathrm{C}$ at a radius of $1 \mathrm{~cm}$ around the urethra. The steep decrease in temperature is seen at $0.8 \mathrm{~cm}$ from the urethra, measuring $51.8^{\circ} \mathrm{C}$.

The cystourethroscopy performed 2 weeks following treatment showed the prostatic urethra full of necrotic tissue. At 4 weeks the dead prostatic tissue appeared softer. At six weeks the tissue appeared soft and fluffy, like cottonwool. Sluffing of the dead tissue was seen at 4 to 8 weeks. The formation of a cavity was seen at 8 weeks as the prostatic tissue separated. At 12 weeks some debris was still seen present in the prostatic cavity.

Clinical Results :

The clinical study demonstrated on initial analysis of the 1 and 3 months follow up, significant improvement of flow rate and a significant decrease in the Madsen symptom score. A significant improvement is defined as a change of $50 \%$ or more.

3 month results were analyzed for 12 patients form one site* with an average symptom score of 14 , an average peak flow rate of $7.3 \mathrm{ml} / \mathrm{sec}$ and residual volume of $262 \mathrm{ml}$ (mean value). The Madson symp tom score significantly improved in all 12 patients to $=/<8 \quad(100 \%$ improvement $)$, the average improvement was from 14 to 4 . The peak flow rate significantly improved to a mean value of $14.6 \mathrm{ml} /$ sec. The postovoid residual volume significantly improved to $56 \mathrm{ml}$ (mean value).

1 and 3 month results for 11 patients from another site were analyzed. In these patients the Madsen symptom score improved from an initial mean value of 30 to 18 , after 1 month, i.e. an average improvement of $40 \%$. At the 3 month follow up the symptom score dropped further to a mean value of 14 , with an average improvement of $53 \%$. The peak flow rate increased from a mean value of $3.25 \mathrm{ml} / \mathrm{sec}$ prior to treatment to a mcan value of $9.36 \mathrm{ml} / \mathrm{sec}$, at one month follow up. This is a significant improvement in $100 \%$ of the patients. The flow rate improved further to a mean value of $10.7 \mathrm{ml} / \mathrm{sec}$ at the 3 month follow up.

The residual volume decreased significantly and improved from an initial mean value of $201 \mathrm{ml}$ before treatment to an average of $64 \mathrm{ml}$ at 1 month, this is an average improvement of $68 \%$.

The patients were grouped according to the Madsen and Iversen evaluation oriteria of residual volume. Before treatment 6 patients were grouped in the $100 \sim 500 \mathrm{ml}$ residual volume group and $83 \%$ of these patients improved to the $50 \sim 100 \mathrm{ml}$ group. 5 patients were grouped in the $50 \sim 100 \mathrm{ml}$ group prior to treatment and 3 of these patients improved to the $<50 \mathrm{ml}$ residual volume group.

All 11 patients were candidates for TURP prior to treatment, according to the Madsen and lversen clinical evaluation criteria. At the 1 month follow up 8 out of the 11 patients (73\%) were no longer eligible for surgery and at the 3 month follow up 5 out of 6 patients $(83 \%)$ were no longer eligible for surgery.

Combined Study :

From a combined study of 23 patients, one month results are available for 17 patients and 3 month results for 18 patients, pooling the results from the above sites.

The peak flow rate increased from an average value of $5.3 \mathrm{ml} / \mathrm{sec}$ to $9.7 \mathrm{ml} / \mathrm{sec}$ at 1 month and improved further to $13.3 \mathrm{ml} / \mathrm{sec}$ (mean value) at 3 months (Fig. 3). $82 \%$ of the patients improved their

* Mr. Shiv Bhanot, M.D., K.M. Grigor, T.B. Har greave, G.D.

Chisholm, University Dept. of Surgery \& Urol., Western General Hospital, Edinburgh, Scotland. Prof. S. Arap, Dr. P. Goes, Hospital das Clinicas, Universidad de Sao Paulo, Brazil. 
Fig. 3 COMBINED STUDY

Symptom Score

3 Month Results--18 Patients

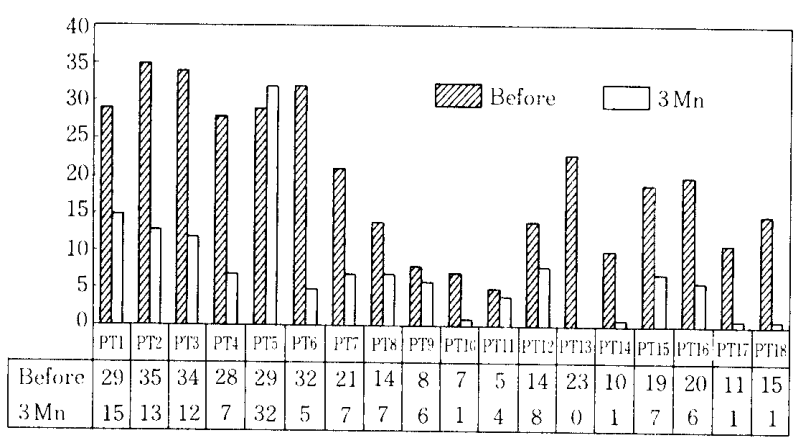

Fig. 4 COMBINED STUDY

Peak Flow Rate

3 Month Results-18 Patients

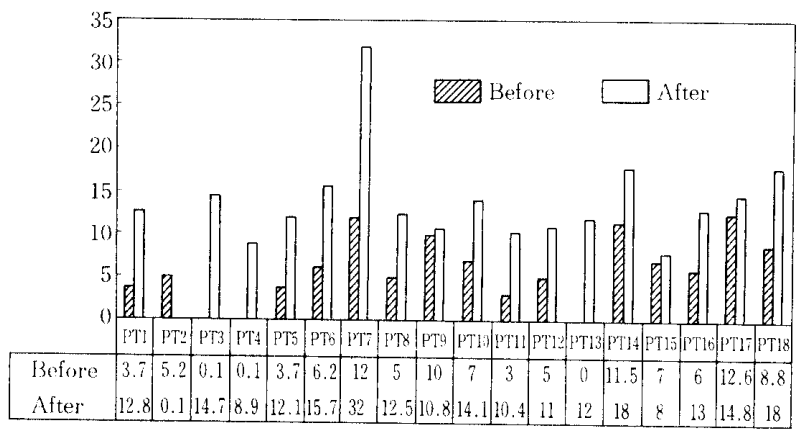

Fig. 5 COMBINED STUDY

Residual Volume ( $\mathrm{ml}$ )

3 Month Results--18 Patients

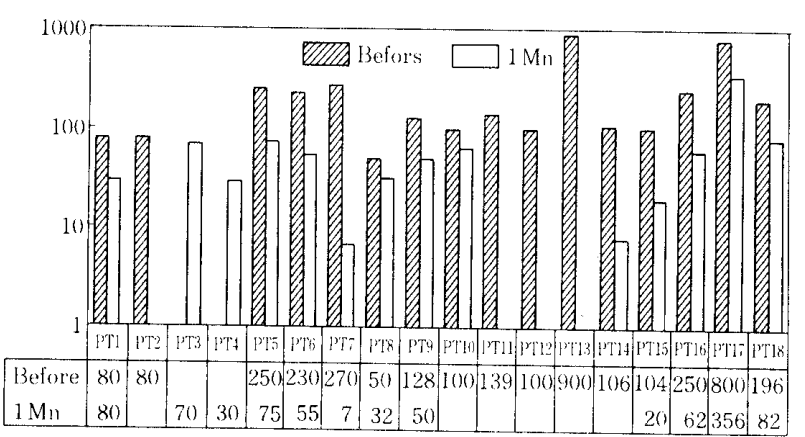

flow rate bvy more than $50 \%$ by the 1 month follow up. Postvoiding residual volume significantly im. proved from a mean value of $181 \mathrm{ml}$, with 3 patients in retention to $78 \mathrm{ml}$ (no retention) at 1 month. The 3 month results of residual volume improved to a mean value of $52 \mathrm{ml}$ and 1 patient in retention (Fig. 4). The symptom score significantly improved from 22 to 7 (mean values) at the 3 month follow up (Fig.
$5)$.

$100 \%$ of the 23 patients were eligible for surgery before treatment. Three months following Turapy treatment, $94 \%$ of the patients were no longer eligible for surgery according to the Madsen and Iversen evaluation criteria.

Discussion

The well observed tolerance of the Turapy treatment may be explained by the fact that the sensory nervous receptors have been ablated by heat early during the treatment allowing susequent painless thermoablation of the prostatic tissue.

The results of the interstitial thermal mapping measurements have demonstrated the safety of the temperature distribution in the prostate with high temperatures concentrated in the area of the pros. tatic urethra and low temperatures in the rectal area.

The post treatment morbidity with Turapy appears to be slightly higher than observed with previous modalities of thermotherapy. This is clearly explained by the extensive tissue destruction in the urethra that leads to temporary micturation difficulties. In all but four patients these symptoms improved spontaneously. The four patients in whom the irritative symptoms persisted, at least two patients improved following antibiotic treatment of urinary infection.

The histopathology evidence clearly indicates the effectiveness of creating a cavity within the prostatic urethra by thermoablation of a significant proportion of the prostate gland. In addition, these studies have shown feasibility, safety to adjacent organs and absence of lesions of surrounding tissues.

The significant improvement in symptoms score, as well as peak flow and residual volume clearly indicate the clinical effectiveness in relieving the patient of irritative as well as obstructive symptoms of benign prostatic hyperplasia.

The histopathological and clinical results show that thermoablation with TURAPY - TransURethral Abiation Prostatectomy is a safe and effective treatment for correction of prostatic obstruction. 
The advantages of TURAPY compared to TURP or laser are numerous. TURAPY is a simple oupatient treatment ; causing no bleeding, irrigation and aneasthesia are not needed and the treatment is well tolerated.

The clinical results establish Turapy as an effective treatment of $\mathrm{BPH}$, in relieving patients of irritative symptoms as well as obstructive parameters, in a single, anesthesia free, 1 hour outpatient session.

\section{References}

1) Broskewit? $\mathrm{RC}$, Larsen EH, Madsen PO, Doriflinger $\mathrm{T}: 3$ year follow up of urinary symptoms after TURP. J Urol $1986 ; 136 ; 613$.

2) Mebust WK, Holtgrewe HL, Cockett ATK ; Transurethral erative study of 13 participating institutions evaluating 3885 patients. J Urol $1989 ; 141 ; 243$.

3) Lepor II ; Nonoperative management of benign prostatic hyperplasia. J Urol 1989；141：1283.

4) Bosch RJLII, Griffiths DJ, Blom JHM, Schroeder FH ; Treatment of benign prostatic hyperplasia by androgen deprication: Effects on prostate size and urodynamic parameters. J Urol. $1989 ; 141: 68$.

5) Lepor H, Shapiro E: Characterization of alpha 1 adrenergic receptors in human benign prostatic hyperplasia. J Urol $1984 ; 132: 1226$.

6) Reddy PK, Wasserman N, Castreneda F, Castreneda-Zuniga WR: Balloon dilation of the prostate for treatment of benign hyperplasia: Urol Clini NB. Am 1988; 15:529.

7) Klein LA, Lemming B: Ballon dilation for prostatic lbstruction: Long-term follow-up. Urology $1989 ; 33: 198$.

8) Keane PF, Chorig CR, Hudd C, Shah JR, Kelett MJ, Boyle J, Wickham JEA, O'Donoghue EPN : Balloon dilation of the prostate: Technique and early results. Br J Urol 1990; 65:354-356.

9) Nissenkorn I., Richter S., Slutzker D: A simple self-retaining intraurethral catheter for treatment of prostatic obstruction. Eur Urol 1990; $18: 286$

10) Schulman C.C., Vandenbosshe M., Peltier A.; (TURF) Transurethral Radiofrequency Heating for BPH at Various Temperatures with Thermex II: Clinical Experience; Eur. Urol
$1993 ; 23 \div 302 \cdots 306$.

11) Nissenkorn I., Rorbard M., Slutzker D., Bernheim $\mathrm{J}$.; Connection Between the Length of the Heating Antenna and Volume of the Prostate in Transurethral Thermotherapy for BPH ; Eur. Urol $1993 ； 23: 307-311$.

12) Corica A, Marianetti A, Anchelerguez R, Pratts J, Corica L, Grau D, Nigro E, Filice R ; Tranurethral Radio Frequency Thermotherapy for Symptomatic BPH; Eur Urol 1993;23: $312-317$.

13) Viguier JI., Dessouki T, Castelo A, Martin X, Marechal JM, Gelet A, Dubernard JM; BPH Treatment by Transurethral Radio Frequency Hyperthermia with Thermex II; Eur Urol $1993 ; 23: 318^{--321 .}$

14) Yazicioglu AH, Dalva I, Ozgur S, Cetin S; Results of Deep Prostatic Hyperthermia Applied with Trermex II in 525 Benign Prostatic Hyperplasias; Eur Urol 1993;23: $322-325$.

15) Smith PH, Chaussy C, Conort P, Devonec M, Milroy R, Nording E, Perez Castro E, Rigondet G, Tazaki H, Vallancien G, VanErps P, and Zerbib M : Report of the Committee on other non medical treatment in proceedings of intrenational consultation on benign prostatic hyperplasia (BPH). Paris-June 26-27, 1991, $225-257$.

16) Marberger M, Editorial Eur. Urol. Suppl. 1993 : 23 (suppl 1) : 1 .

17) MeCulloch DL et al : Tulip-transurethral ultrasound guided laser induced prostatectomynational human cooperative study results; $\mathrm{J}$. Urol. $1992 ; 147$ (suppl) : 306A.

18) Madersbacher S, Kratzik C, Szabo N, Susani $M$, Vingers $L$ and Marberger $M$ : Tissue Ablation in BPH with High Intensity Focussed Ultrasound: Eur Urol $1993 ; 23$ (suppl) : $39-43$.

19) Vallancien G, Chartier-Kastler E, Bataille N, Chopin D, Harouni M, and Bourgarin J : Focussed Extracorporeal Pyrotherapy: Eur Urol 1993 ; (suppl 1) : 48-52.

20) Madsen PO, \& Iversen P.; Point system for selecting operative candidates In ; Benign prostatic hypertrophy. Hinman F., editor, Springer Verlag, 1983, 763-765. 